\title{
O LETRAMENTO LITERÁRIO E A EDUCAÇÃO DE JOVENS E ADULTOS
}

\author{
The literary literacy and the education \\ of young people and adults
}

\section{Carmem Lucia E iterera, Juliana Valéria de Abreu ${ }^{\mathrm{b}}$}

a D outora em Educação e Professora adjunta da FAE/ UFMG, Belo Horizonte, BH Brasil, e-mail: eiterer@ oi.com.br

${ }^{\text {b }}$ Pedagoga, Mestranda em Educação pela FAE/ UFMG, Belo Horizonte, BH - Brasil, e-mail: julianavaleria1@yahoo.com.br

\section{Resumo}

Este artigo pretende tratar da presença da atividade de leitura da literatura na modalidade de ensino EJA. Para isso, apresentamos a seguir um balanço do Projeto Clube de Leitura. A fim de contextualizar tais atividades e justificá-las optamos por, primeiramente, apresentar um breve panorama da EJA no Brasil. A seguir, apresentamos o Programa de Educação de Adultos da UFMG e o Proef-2, onde se desenvolveram as atividades que pretendemos relatar. Este projeto de extensão, o Clube de Leitura, proposto e coordenado por esta pesquisadora, por sua natureza, não faz parte do Programa de Educação Básica de Jovens e Adultos da UFMG, mas é uma atividade independente que acontece dentro dele. D esenvolvemos durante todo 0 ano de 2006, atividades de leitura livre de textos literários, mediada sempre por uma bolsista, sem cobranças de provas, de produção escrita, interpretação ou mesmo controle de presença. Tais cuidados visam garantir a superação das distâncias entre livro e leitor nessa modalidade de ensino, buscando promover situações voltadas ao fortalecimento do letramento literário de um grupo de 30 jovens e adultos alunos deste Projeto de Ensino Fundamental - Proef-2.

Palavras-chave: Leitura. Literatura. Educação. Adultos.

Rev. D iálogo Educ., Curitiba, v. 9, n. 26, p. 149-160, jan./ abr. 2009 


\begin{abstract}
This paper discusses the need of the literature activities in adult education. We present the analysis of some activities developed at The Reading Club Project, an extension project developed throughout 2006 which involved young and adult students. The Reading Club aimed at strengthening students' literary literacy. In this paper, we first present a brief description of adult education in Brazil. Then, we present the context of the project, which was the Adult Education Program at UFMG and PROEF-2 where have developed activities that we want to report. This extension project, proposed and coordinated by this researcher, by their nature, is not part of the program of UFMG basic education of young people and adults, but it is an independent activity that happens inside it. We have developed throughout 2006 free reading activities of literary texts, always mediated by a scholarship holder, without examinations or presence control. Such care to ensure that the distances between book reader in this mode of education, seeking to promote situations focussed on strengthening of literary literacy of a group of 30 youths and adults students of this project school-PROEF-2.
\end{abstract}

Keywords: Reading. Literacy. Adult. Education.

A defesa do direito à educação foi a principal bandeira de luta para o campo da Educação Popular, ou Educação de Adultos até 1988, quando se deu a promulgação da Nova Constituição brasileira. D efender o direito à educação significou, até este momento, não apenas a defesa do direito à alfabetização, mas, principalmente, a garantia da possibilidade de continuidade de estudos para estes educandos que compunham uma população que vinha desde a década de 40 sendo atendida unicamente por campanhas de curta duração e sem continuidade.

A oferta de escolarização nessa modalidade de ensino hojeéobrigatória e de responsabilidade dos Municípios e Estados, para adultos e também parajovens que não concluíram sua escolaridade no período regular. A inclusão destes novos sujeitos leva a criação de uma nova modalidade de ensino, a EJA - Educação de Jovens e Adultos. A ação do G overno Federal no sentido da extensão deste direito criou ainda em 2005 a obrigatoriedade de atendimento no nível médio profissionalizante em EJA, no período noturno, através das escolas técnicas federais.

Rev. Diálogo Educ., Curitiba, v. 9, n. 26, p. 149-160, jan./ abr. 2009 
Assim, após a conquista e consolidação do direito subjetivo na legislação, ${ }^{1}$ com a oferta de vagas para alunos jovens e adultos nas escolas públicas pela esfera do poder público, passamos a uma nova etapa na defesa da Educação para Jovens e Adultos. Com 0 atendimento às demandas sociais por escolarização, os pesquisadores no campo voltaram-se a novos problemas de investigação. São as novas questões que emergem das práticas pedagógicas que começaram a se configurar nessa modalidade de ensino.

O panorama no âmbito da EJA tem mostrado que, algumas vezes, 0 ensino tem significado ofertar aos alunos jovens e adultos, nos conteúdos e métodos, o mesmo ensino que se oferta no formato chamado "regular", sem que se atente às necessidades específicas e as identidades deste público. Temos verificado, apesar de já estarmos a mais de 15 anos da publicação do artigo 208, a carência nas escolas de materiais adequados (livros didáticos etc.), bem como de profissionais formados dentro desta especialidade para atender ao adulto como adulto que é, e não a partir de uma oferta de um ensino desconexo de seu contexto de vida e trabalho. O u seja, surge a questão agora de acompanhar e planejar a escolarização destes jovens e adultos e como se formam os professores que atuarão neste campo. Configurando uma nova realidade que passa a ser o foco das investigações. Distingui-se a EJA enquanto campo que reflete sobre a educação de jovens e adultos e a esolarização desses sujeitos, dentro dele:

A educação de adultos engloba todo o processo de aprendizagem, formal ou informal, onde pessoas consideradas "adultas" pela sociedade desenvolvem suas habilidades, enriquecem seu conhecimento e aperfeiçoam suas qualificações técnicas e profissionais, direcionando-as para a satisfação de suas necessidades e as da sua sociedade. A educação de adultos inclui a educação formal, a educação não-formal e o espectro de aprendizagem informal e incidental disponível numa sociedade multicultural, onde os estudos baseados na teoria e prática devem ser reconhecidos. (PAIVA, 2004, p. 42). ${ }^{2}$

1 O artigo 208 da Nova Constituição estabelece o dever do Estado com o ensino fundamental "obrigatório e gratuito, inclusive para os que não tiveram acesso na idade própria."

2 A D eclaração de Hamburgo é um importante documento nascido da V Confitea - Conferência Internacional de Educação de Adultos, Hamburgo, Alemanha, 1997. Referência para a área, cfe. destaca SOARES, 2004. p. 280, foi um marco teórico, inaugurando a concepção de educação como processo de formação ao longo da vida, superando as idéias de suprimento e de educação compensatória, presentes nas conferências anteriores.

Rev. D iálogo Educ., Curitiba, v. 9, n. 26, p. 149-160, jan./ abr. 2009 
Nesse sentido o projeto busca atuar segundo o seguinte propósito

O ferecendo a funcionários da Universidade e a jovens e adultos da comunidade em geral, a oportunidade de escolarização de qualidade e apropriada a esse público no nível da Escola Fundamental, aos estudantes dos cursos de licenciatura (bolsistas e estagiários) a iniciação orientada à atividade profissional no campo pedagógico, e a professores e pesquisadores um espaço privilegiado para investigação, este Projeto legitima e subsidia a produção de conhecimento e diversas iniciativas e ações de Educação de Jovens e Adultos (EJA), promovidas pela UFMG ou com seu apoio. (SOARES, 2004, 9-26).

Neste projeto, como coordenadora de área de ensino de história, durante os últimos 4 anos, acompanhamos as atividades dos monitores-bolsistas que atuam como educadores, discutindo, semanalmente, as estratégias, conteúdos, dificuldades e expectativas em relação às práticas pedagógicas, à organização das aulas, à relação professor-aluno. As coordenações de área buscam construir com os graduandos alternativas para uma ação educativa criativa, interdisciplinar e orientada para a vida. Incentivando, também, a reflexão, a produção de conhecimentos sobre suas experiências docentes, a participação em congressos e seminários para troca destas vivências com outros educadores.

Para muitos professores, as interrogações que vieram das vidas dos jovens-adultos são uma nova luminosidade para rever os conhecimentos escolares. Apostam que novas formas de garantir o direito ao conhecimento são possíveis quando os educandos são jovens e adultos que, em suas trajetórias, carregam interrogações existenciais sobre a vida, o trabalho, a natureza, a ordem-desordem social, sobre sua identidade, sua cultura, sua história e sua memória, sobre a dor, 0 medo, o presente e o passado. Sobre a condição humana. Interrogações que estão chegando à docência, aos curnículos, à pedagogia. Quando o diálogo é com percursos humanos tão trancados dejovens - adultos populares, essas interrogações podem se tornar mais prementes. Exigem resposta. (ARROYO, 2005, p. 39).

A proposta de trabalho que aqui apresentamos, realizada no âmbito do Proef, orienta-se na procura de respostas tão centrais no campo daEJA, visando contribuir para a formação do aluno adulto, do ponto de vista de sua atividade de leitor, especificamente, como leitor de literatura.

Rev. Diálogo Educ., Curitiba, v. 9, n. 26, p. 149-160, jan./ abr. 2009 
A formação de leitores na escola foi tema de investigação no Mestrado e D outorado de uma das autoras, com pesquisa sobre leitura nas salas de aula de Filosofia no Ensino Médio, numa escola pública estadual paulistana no período noturno (EITERER, 1996) e junto a alunos da Escola de Aplicação da Faculdade de Educação da USP (EITERER, 2001). Em comum, as duas pesquisas tiveram o fato de se dedicarem a investigar a formação do leitor no nível médio da Escola Básica intermediada pela discussão literária. Em ambos os casos, uma obra literária foi adotada como ponto de partida para leitura comum e discussão a partir da qual se fez a investigação.

A atuação junto à EJA na UFMG, fez com que, cada vez mais, 0 campo do letramento literário se apresentasse como relevante para esta pesquisadora, sobretudo, se considerarmos a ausência de estudos do ponto de vista da leitura literária que esses jovens e adultos alunos da EJA realizam.

Assim, partimos do pressuposto de que os alunos de EJA, no $2^{\circ}$ segmento do Ensino Fundamental, Proef-2, são leitores, e, como leitores, passamos a trabalhar com eles o Projeto Clube de Leitura, voltado a efetuar e partilhar leituras literárias. Este projeto de extensão, por sua natureza informal, não faz parte do currículo do Programa de Educação Básica de Jovens e Adultos, é uma atividade independente que acontece dentro do mesmo espaço. D esenvolvemos, durante todo 0 ano de 2006, atividades voltadas ao letramento literário de um grupo de 30 jovens e adultos alunos deste Projeto de Ensino Fundamental - $2^{\circ}$ segmento, o Proef- 2 .

\section{Por que pensar o letramento literário na EJA}

A preocupação com a formação do leitor e os níveis de leitura no país responde pelo fato de encontramos um grande número de pesquisas acerca da temática da formação de leitores na escola básica, particularmente no que se refere ao leitor infantil e juvenil. D esde a década de 90 , os pesquisadores voltaramse também para a investigação das leituras dos professores emesmo dos professores em formação inicial, considerando-se que eles atuarão como mediadores da leitura nos processos de formação na escola.

Encontramos ainda pesquisas que, para além da leitura escolar, voltam-se para a vida de alunos e suas famílias pertencentes a meios sociais e economicamente considerados desprivilegiados. São encontrados bilhetes, cartas, agendas, recados, listas de compras, recortes etc., compondo uma multiplicidade de usos e funções do escrito permeando o cotidiano dos sujeitos (LAHIRE, 1993). Estes estudos demonstram que há usos sociais de leitura e escrita perpassando a sociedade de diferentes maneiras e que há diferentes leitores/ escritores nos mais diversos meios socioeconômicos e culturais.

Rev. D iálogo Educ., Curitiba, v. 9, n. 26, p. 149-160, jan./ abr. 2009 
Começaram a surgir, nos últimos anos, investigações sobre 0 letramento na EJA, no entanto, a literatura na escolarização de jovens e adultos é ainda um campo a ser estudado.

D eacordo com Magda Soares (2002), o conceito de letramento surgiu no Brasil, em contraposição ao termo literacy em uso em países de língua inglesa ou o termo literacia em Portugal, a partir da necessidade de nomear o fenômeno constituído pelo conjunto das práticas sociais de leitura e escrita. 0 conceito indica uma capacidade, ação ou processo: "Letramento é pois, o resultado da ação de ensinar ou de aprender a ler e escrever: o estado ou a condição que adquire um grupo social ou um indivíduo como conseqüência de ter-se apropriado da escrita" (SOARES, 2002, p. 18).

0 termo letramento indica uma gama de práticas sociais no âmbito da cultura escrita nas quais os sujeitos podem se engajar. Podemos falar na presença de diferentes níveis de letramento numa sociedade, pois o conceito cobre uma vasta gama de usos e graus de interação com a cultura escrita. Por exemplo, ainda que não haja alfabetização, ou seja, mesmo que não haja um domínio do código escrito, nossa sociedade, tipicamente letrada, coloca os sujeitos em constante interação com textos em diversos formatos e diferentes suportes.

Para quem vive em sociedades como a nossa, complexa, em que tudo se organiza pela escritura e em torno dele, mesmo sem dominar o código, não há como escapar das armadilhas do texto. Todos os sujeitos são atravessados pelo sistema da escritura, o que os obriga a produzir saídas e táticas. (PAIVA, 2003, p. 118).

E também podemos falar em letramento matemático, literário, científico, musical. Paulino (2004), discutindo a dimensão do letramento literário, resgata as décadas de 80 e 90 para mostrar como o fim da Guerra Fria traduziu-se no meio acadêmico na forma de estudos culturais, ou da valorização do micro, das culturas etc. Nesse bojo, uma valorização antropológica da cultura colocaria os cânones literários em questão. Para a autora, entretanto, nivelar autores e textos em nome da crítica da ideologia pode revelar-se também um mecanismo de exclusão. Textos não são todos iguais como também autores e leitores não são todos iguais.

Entendemos que ler é um processo de ressignificação do texto e, como Paulo Freire em A importância do ato de ler, algo que começa antes do texto, e vai além dele:

A leitura do mundo precede a leitura da palavra, daí que a posterior leitura desta não possa prescindir da continuidade da leitura daquela. Linguagem e realidade

Rev. Diálogo Educ., Curitiba, v. 9, n. 26, p. 149-160, jan./ abr. 2009 
se prendem dinamicamente. A compreensão do texto a ser alcançada por sua leitura crítica implica a percepção das relações entre o texto e 0 contexto. (FREIRE, 1999, p. 11).

A experiência estética, no entanto, é muitas vezes suprimida em práticas escolares inadequadas (EVANGELISTA, 2001). Mas, acreditamos que muitos dos problemas de leitura no Brasil são problemas gerados pela falta de acesso a livros e material de leitura literária de qualidade, por seu alto custo e pela carência de espaços públicos de leitura. É fato, no entanto, que uma atitude de valorização da leitura socialmente partilhada e o valor atribuído à literatura respondem por podermos encontrar leitores insuspeitados, como muitas pesquisas mostraram, e mesmo nas nossas próprias investigações anteriores pudemos comprovar.

No II Colóquio Luso-Brasileiro de Currículo, realizado na UERJ, no Rio de Janeiro em agosto de 2004, a Prof ${ }^{a}$ Magda Soares proferiu conferência em que o direito à igualdade no acesso à escola, aos bens culturais e simbólicos recorrendo ao chamado "Efeito Matheus", hipótese sociológica baseada na parábola dos D ez Talentos, narrada no Evangelho de Mateus, segundo a qual: "àquele que tem, mais lhe será acrescentado, e ao que não tem, mesmo o pouco que tem lhe será tirado."

0 "efeito Matheus" nos vem frequentemente à memória quando nos remetemos à leitura. Se na modalidade "regular" de ensino o trabalho que é feito na escolarização da literatura produz por vezes efeitos danosos e mesmo permanentes na convivência entre o leitor e o livro literário, na EJA estes efeitos são ainda mais drásticos. A memória do sofrimento anterior é um obstáculo a mais, que mantém 0 aluno adulto longe deste objeto na sua volta para a escola.

Como tratamos em outro texto (COELHO; EITERER, 2006, p. 3), 0 aluno tem expectativas em relação à escola que o fazem antecipar (ainda que com temor), o que ali deve acontecer:

Uma dimensão dos saberes prévios dos alunos no seu retorno à escola, que devemos considerar são suas representações de escola, aula, professor e aprendizagem etc. De fato, a relação do aluno com o conhecimento escolar na EJA constitui um aspecto importante [...]. Trata-se de noções acerca do que é uma aula e de como ela se processa, do que são conteúdos escolares e avaliação, entre outros.

0 adulto, anteriormente "expulso" da escola, retorna com a crença de que nada sabe e que deve aprender com o professor, legítimo detentor do conhecimento válido, almejando as mesmas práticas de quando saiu da escola, ainda que estas sejam em boa parte as responsáveis por seu anterior fracasso escolar.

Rev. D iálogo Educ., Curitiba, v. 9, n. 26, p. 149-160, jan./ abr. 2009 
Espera obter informações de um mundo distante do seu, marcado por nomenclaturas que ele considera próprias de quem sabe das coisas. [...], acham que o professor ensina só quando fala de coisas sobre as quais eles não tenham a menor idéia. (CARLOS; BARRETO, 1995, p. 34).

Como romper a distância livro-leitor, sem resgatar velhas práticas que, na verdade sempre estiveram a serviço de mantê-lo afastado desta relação com a literatura? Na busca desta resposta o Clube de Leitura existe desde o dia 15 de março de 2006.

\section{Clube de Leitura}

O Clube de Leitura são encontros de leitura literária que acontecem no Centro Pedagógico da UFMG, trinta minutos antes do início das aulas regulares da EJA. D uas vezes por semana, reúnem-se para ler, coletivamente, textos literários. O s encontros acontecem às terças e quartas-feiras em lugares escolhidos pelos leitores, fora da sala de aula, a princípio ao ar livre, depois, a pedido dos próprios alunos, passaram a acontecer na biblioteca do Centro Pedagógico, sem as formalidades geralmente exigidas (por eles mesmos, muitas vezes), em sala de aula. Essa característica é essencial para que as leituras e sua socialização se deem, em um ambiente descontraído, sem avaliações, notas, ou julgamentos.

0 grupo que se formou a partir de convites informais, avisos em sala de aula e cartazes no Proef-2, tem contado com cerca de 30 alunos de EJA, entre homens e mulheres, com idade entre 25 e 72 anos, que têm participado das leituras de textos de reconhecida qualidade literária, de autores reconhecidos, sem resumos, sem recortes e sem adaptações.

A leitura é realizada em voz alta pela bolsista de extensão, ex-aluna de Pedagogia, e por alunos que manifestem o desejo de ler, com o acompanhamento dos demais nos livros ou em cópias do texto entregue no início do encontro. O ptamos por distribuir as cópias de modo que pudessem acompanhar a leitura quando não houvesse um número suficiente de exemplares disponíveis na biblioteca para atender a todos.

A preparação dos encontros é feita previamente, quando os textos são selecionados e, quando necessário, copiados. Os critérios de escolha foram trabalhar com textos curtos, contos, crônicas, poemas de linguagem acessível, de autores clássicos de literatura brasileira. Inicialmente, fizemos uma sondagem com o grupo acerca das experiências de leitura literária, constatando que, com exceção de dois alunos, a maioria do grupo não costumava ter contato com esse tipo de texto. A explicação que deram foi falta de tempo, falta de hábito, falta de interesse e dificuldade de compreensão.

Rev. Diálogo Educ., Curitiba, v. 9, n. 26, p. 149-160, jan./ abr. 2009 
A proposta então, tomou forma, ler sem compromisso com notas ou cobranças quanto à interpretação, ou compromisso com uma leitura perfeita; pretendiase ler buscando o prazer que o texto literário pode despertar, ler pela arte de um texto bem escrito, ler porque enriquece nosso repertório, "abre nossa mente" para outras perspectivas e assim aprendemos a lidar melhor com nosso próprio cotidiano.

No primeiro encontro, levamos um conto de Machado de Assis, conversamos sobre o vocabulário diferenciado que encontraríamos no texto, sobre a época que 0 autor viveu, sua maneira peculiar de escrita e as dificuldades que alguns alunos apresentaram com leituras anteriores do mesmo autor. Optamos por começar com Machado justamente por seu lugar de destaque como clássico nacional, que o faz sempre figurar nas listas de textos a serem lidos, nas escolas e fora delas, e para quebrar resistências e preconceitos com relação tanto a este autor quanto a este gênero de textos. $\mathrm{O}$ u seja, selecionando contos como Idéias de Canário, entre outros, de natureza curta e de aguda crítica social, procuramos demonstrar que podíamos ler, entender e nos divertir com a companhia dos textos de Machado. Isso se deu aos poucos, sem exigências, sem compromissos.

Com pouco mais de um mês do Clube de leitura, o grupo se tornou frequente, e demonstram alguns avanços, se pudermos assim dizer, do ponto de vista de sua relação com a leitura. Os relatos dos alunos são de que gostam e insistem com outros colegas para irem acompanhá-los; de comentários na empresa onde um deles trabalha, de que existe o 'clube' e que "agora está aprendendo a ler de verdade" e de gente que passou a ler a bíblia diariamente em voz alta porque quer melhorar a sua leitura no grupo.

Optamos inicialmente por nos manter fora da biblioteca para não intimidar ninguém, mas já verificamos que ela passou a ser um espaço de desejo desses leitores, alguns passaram a visitá-la, optamos, então, por continuar nossos encontros nela, que é uma biblioteca ampla, bem iluminada, confortável e arejada, um espaço bastante favorável à descontração que caracteriza a atividade. Outros alunos perguntaram sobre o livro que estávamos lendo, se conseguiam na biblioteca para continuar a ler em casa; um perguntou como se faz para escolher um livro na biblioteca em meio atantos e ainda houve quem relatasse que agora está "começando a entender os textos que lê, antes, acabava de ler e não entendia nada."

Do mesmo modo que optamos por iniciar com textos curtos, verificamos que, no decorrer das atividades, o livro passou a ser objeto de desejo, e os alunos começaram a perguntar quando leríamos um livro inteiro. Foi aí que, para favorecer esse encontro entre livro e leitor, optamos pela leitura de um texto de um autor contemporâneo, que falasse a linguagem dos nossos leitores, para que a leitura fosse agradável e acessível, dialogando com esses leitores e suas experiências de vida. D aí a escolha do livro Indez de Bartolomeu Campos de Q ueirós (1989).

Rev. D iálogo Educ., Curitiba, v. 9, n. 26, p. 149-160, jan./ abr. 2009 
A leitura de Indez foi bastante significativa e mesmo essencial para que alguns leitores descobrissem o quanto pode ser agradável e divertido um livro de literatura. Por ser um relato de infância do próprio autor no interior de Minas $\mathrm{G}$ erais, os adultos viram-se seduzidos, identificaram-se com fatos narrados, como as "receitinhas caseiras" que curavam qualquer dor de barriga ou bicho-depé, assim como aquelas que faziam a comida render e matar a fome. Também as peraltices da personagem, a vida simples, e as dificuldades vividas pelos pais dessa, lhes pareceram muito próximas.

Nessa ocasião, conseguimos a doação de alguns exemplares do livro pela editora Global, de modo que os alunos receberam e levaram os livros para casa, socializando-o com parentes, amigos e vizinhos, segundo relato deles próprios. A leitura foi permeada por risos, comentários e lembranças. A empatia levou-os, ao final da leitura, a optarem por ler outro livro do mesmo autor, L er, escrever, fazer onta de cabeca.

Nosso projeto então culminou com um encontro com esse autor na biblioteca da escola, em um bate-papo descontraído em que vários alunos fizeram todo tipo de perguntas, e contaram como a leitura lhes foi prazerosa e significativa, até mesmo partilharam um pouco de suas lembranças. $\mathrm{O}$ autor, solícito, respondeu as perguntas, ouvindo e contando sua história e, principalmente, apresentando a trajetória e oficio de escritor.

\section{À GUISA DE CONCLUSÃO}

Se ler é uma habilidade que se desenvolve lendo, tais leituras têm sido oportunidade de contato importante dos textos e autores com este público, e mais do que nunca, esse espaço se constitui como espaço privilegiado da relação do aluno jovem e adulto na EJA com a literatura. Avaliamos o retorno do projeto como muito positivo. Especialmente na semana seguinte ao encontro com o autor, estavam todos animados e cheios de coragem e desejo de começarem a leitura "de mais um livro", como disseram.

Alguns dão sinais de mudança e envolvimento com a literatura, começam a sempre ter um livro na bolsa. Outros manifestam gostar das leituras nos encontros, ainda não adquiriram autonomia de leitores, mas não faltam a um encontro. Ainda há outros que relatam o quanto as nossas leituras influenciaram na compreensão dos textos escolares, relatam que agora conseguem apreender 0 que leem. Nunca tivemos a pretensão de ensinar teoria literária ou história da literatura, mesmo a biografia do autor é abordada apenas num nível que possa levar a despertar a curiosidade de futuros leitores. Cremos, no entanto, que embora aparentemente muito simples, tais ações são necessárias e por esta razão procuramos continuar em 2007.

Rev. Diálogo Educ., Curitiba, v. 9, n. 26, p. 149-160, jan./ abr. 2009 
Entendemos que a literatura é um bem cultural a que nossos alunos adultos (assim como as crianças e jovens), têm direito. E a escola precisa atentar ao desenvolvimento de práticas que procurem aproximar o leitor do texto. Aulas de literatura que na verdade em sua maioria se revelam aulas de história da literatura não substituem ações de promoção da leitura. A transformação do texto em tarefa, segundo receitas de vestibulares e outras, não pode vir a ser também a única via à disposição desses sujeitos. D a mesma maneira que atividades que conjugam leitura e prazer não podem estar restritas aos anos iniciais do Ensino Fundamental ou à Educação Infantil. Assim como as mudanças que se produzem nos regimes de leitura, na quantidade e qualidade dos textos lidos, bem como nas funções da leitura, ao longo dos anos escolares, não podem concorrer para reverter aquilo que a custo se consegue com a criança pequena, quando se consegue.

Deste modo, defendemos que a leitura literária é uma dimensão significativa da cultura, nos instiga, mexe com nosso íntimo, nos remete a lembranças, nos faz refletir, repensar a realidade e nos "tira do lugar-comum", projetando futuros possíveis. Possibilitar encontros significativos com a literatura brasileira, com os nossos autores mais consagrados, na EJA, é o que desejamos, uma vez que, mediar 0 acesso à literatura é também abrir portas ao desconhecido, ao inusitado, ao imaginário.

Entendemos que para além da leitura funcional, de uso do dia-adia, a literatura perfaz uma dimensão humana necessária que se mantém afastada dos leitores adultos alunos da EJA não apenas por questões econômicas, mas também sociais, culturais e geográficas. O u seja, além dos preços do objeto livro, há os preconceitos e medos, a noção de que isto não é para eles, de que não dão conta de entender, que deve ser enfrentada. Uma vez que, 0 acesso a diversidades de produção numa dada cultura é uma dimensão do direito da pessoa humana que deve ser salvaguardado e defendido na escola.

\section{REFERÊNCIAS}

ARROYO, Miguel G onzalez. Educação de jovens e adultos: um campo de direitos e de responsabilidade pública. In: SOARES, Leôncio et. al Diálogos na educação de jovens e adultos. Belo Horizonte: Autêntica, 2005. p. 39.

ASSIS, Machado. Idéias de canário. Disponível em: <www.dominiopublico.gov.br>. Acesso em: 15 mar. 2006.

CARLOS, José; BARRETO, Vera. Um sonho que não serve ao sonhador. Alfabetização e Cidadania, ano 2, n. 1, p. 31-37, 1995.

Rev. D iálogo Educ., Curitiba, v. 9, n. 26, p. 149-160, jan./ abr. 2009 
COELHO, Ana Maria. Simões; EITERER, Carmem Lucia. A didática na EJA: contribuições da epistemologia de $\mathrm{G}$ aston Bachelard. In: SOARE S, Leôncio et al. D iálogos na educação de jovens e adultos. Belo Horizonte: Autêntica, 2006. p. 3.

EITERER, Carmem Lucia. Filosofia \& leitura: estudo de uma experiência didática em uma escola pública paulistana no período noturno. 1996. 126 f. D issertação (Mestrado em Educação) Universidade de São Paulo, São Paulo, 1996.

. Uma leitura possível: um estudo sobre a formação do leitor no ensino. 2001. 146 f. Tese (D outorado em Educação). Universidade de São Paulo, São Paulo, 2001.

EVANGELISTA, Aracy Alves Martins et al. A escolanização da leitura literária: o jogo do livro infantil ejuvenil. Belo Horizonte: Autêntica, 2001.

FREIRE, Paulo. A importância do ato de ler. São Paulo: Cortez, 1999.

LAHIRE, Bernard. La raison dês plus faibles. Rapport au travail, écritures domestiques et lectures en milieux populaires. Lille: PUF, 1993.

PAIVA, Jane et al. E ducação de adultos: uma memória contemporânea - 1996-2004. Brasília: Unesco, ME C, 2004.

Literatura e neoleitores jovens e adultos: encontros possíveis no currículo? In: PAIVA, A parecida et al. (O rg.). Literatura e letramento: espaços, suportes e interfaces. Belo Horizonte: Autêntica, 2003. p. 118.

PAULINO, G raça. Formação de leitores: a questão dos cânones literários.

Revista Portuguesa de Educação, v. 17, n. 01, p. 47-62, 2004.

QUEIROZ, Bartolomeu Campos. Ler, escrever e fazer conta de cabeça. Rio de Janeiro: G lobal, 2004.

. Indez. Belo Horizonte: Miguilim, 1989.

SOARES, Magda. Letramento: um tema em três gêneros. Belo Horizonte: Autêntica, 2002.

. Curriculo e democracia. In: COLÓ QUIO LUSO BRÁATLEIRO DE CURRÍCULO, 2., 2004, Rio de Janeiro. Anais... Rio de Janeiro: UERJ, 2004.

Recebido: 20/ 07/ 2008

Received: 07/ 20/ 2008

Aprovado: 05/ 09/ 2008

A pproved: $09 / 05 / 2008$

Rev. Diálogo Educ., Curitiba, v. 9, n. 26, p. 149-160, jan./ abr. 2009 